Fecha de recepción: marzo 2009

Fecha de aceptación: abril 2009

Versión final: noviembre 2009

\section{Mobiliario Urbano. Espacio Público. Ciudad - Paisaje}

Felipe Uribe de Bedout*

\begin{abstract}
Resumen: El modesto contorneo del cuerpo es un acto profundamente lírico, una forma de escritura en que cada trayecto que traza es un relato, una historia íntima, un tejer sosegado de memoria que convierte el actor en autor. De este modo se reescribe la experiencia urbana como construcción cultural, desde un encofrado predispuesto para ello, superando, claro, cualquier predicción de comportamiento.
\end{abstract}

Palabras claves: cuerpo - emoción - acción - mobiliario - espacio público - abstracción - ciudadpaisaje - clima - rito - acontecimiento - evento - reacción - cultura urbana.

[Resúmenes en inglés y portugués y currículum en las páginas 107-108]

Partir de la aceptación que el territorio o enclave natural es el recinto por excelencia que contiene a la ciudad parece un enfoque sensato que nos sirve para darle base al postulado de que la ciudad es, ante todo, una sumatoria de itinerarios espontáneos o diseñados, los cuales exigen una consideración o valoración del verbo como principal materia prima para la concepción del espacio público.

Esta es sin duda una mirada que detecta en el acontecimiento -la acción- la fuerza central para motivar el entendimiento de la noción del habitar.

La noción de estar implica entender que tenemos cuerpo y ocupamos espacio, pero a su vez somos seres espaciantes para evolucionar hacia el "habitar". Es desde el territorio, el paisaje o el lugar como se deben delinear los verbos -o las acciones- que permitan generar acontecimientos que a su vez definan los hábitos o ritos del habitante de la ciudad. Estos hábitos o ritos, individuales o colectivos, son los responsables de edificar una cultura urbana.

El rito implica una secuencia de acciones que involucran necesariamente al cuerpo (objeto medible, ser ergonómico). El mobiliario urbano resulta un instrumento privilegiado para direccionar las acciones del ciudadano, ya que es desde el cuerpo que se inicia una interacción con el espacio público. Sin embargo, el amoblamiento debe -por medio de la abstracción- apartarse de un código figurativo reconocible, que no paralice al usuario con un trabajo o una acción en particular. Deben desaparecer los rastros de un estudio ergonómico conductivista preliminar para permitirle al usuario actuar de acuerdo al momento inmediato.

El urbanismo es entonces un problema de milímetros y es desde el mobiliario y el espacio público que lo alberga, que el lugar orienta a la acción desde el cuerpo emocionado, para así afianzar una relación afectiva con el paisaje, desde y hacia la ciudad. 


\section{De una experiencia local a posibles consideraciones universales}

Durante ocho años continuos, he tenido la oportunidad de intervenir el espacio público en la ciudad de Medellín, tiempo suficiente para evaluar la eficacia de algunas reflexiones urbanas, con cierta claridad y serenidad. Esta experiencia nacida de una lectura específica y especial, de una ciudad ahincada en medio de un valle majestuoso y que ha padecido los estragos de una violencia desmedida, puede servir como referencia para algunas consideraciones hoy básicas en el momento de pensar la ciudad.

En estas últimas dos décadas, el espacio público en Medellín ha sido un problema de supervivencia y no de apariencia. Cuando se trata de sobrevivir, los más mínimos detalles son esenciales y exigen una mirada profunda. La convivencia ha sido el objetivo más apremiante sin por ello renunciar a búsquedas tipológicas y plásticas arriesgadas. Ha sido en medio de esta zozobra urbana que he tenido que aplicar estrategias de choque que escapan al planeamiento estructurado y que profundizan en la investigación de los proyectos detonantes. Esto, en ningún momento ha evitado que desde el estudio se formulen proyectos de ciudad que direccionen las intervenciones puntuales.

La condición urbano-social actual de Medellín parece ser una comprobación de la eficacia de algunas de las estrategias implementadas en el proceso de diseño de los varios proyectos que me tocó ejecutar. Las mismas son expuestas en este ensayo a manera de una serie de diecinueve cuestionamientos-reflexiones, la mayoría de los cuales se abren con una cita referente. Aunque, probablemente, algunos de los interrogantes implícitos o explícitos no se encuentren respondidos completamente y las consecuentes reflexiones no representen una respuesta única transferible, los cuestionamientos que las suscitan son definitivamente ineludibles en el momento de abordar cualquier proyecto urbano presente. Los mismos son:

\section{1. ¿Diseñar o pensar la ciudad?}

"Un lugar es siempre una orientación para la acción, o sea una noción, y una modulación en la relación con el cuerpo del otro, o sea una emoción" (Muntañola Thornberg, Joseph. Citado por Beljon en Gramática del Arte)

Si tomamos como referencia la acepción del significado de diseño - de entre las que se exhiben en el texto disparador de este ensayo- la cual se refiere a la "disposición de manchas, colores o dibujos que caracterizan exteriormente a diversos animales y plantas" y si se mira más ampliamente y se extiende su significado al territorio natural donde se asientan las ciudades, se tendría que aceptar la valoración primordial de lo sustantivo y la anulación del verbo como materia prima de los procesos de diseño de la ciudad. Es evidente que se entraría en una contradicción clara con la cita que abre esta primera reflexión.

Es interesante mirar con detenimiento otra de las acepciones relacionadas del significado de diseño, la cual se refiere al proyecto como "plan de cualquier trabajo". Es claro que la idea de trabajo nos remite a la idea de acción y no de simple apreciación.

Resulta entonces apremiante reemplazar la noción de diseñar la ciudad entendiéndola como una disposición de manchas o áreas caracterizadas, por una que implica o requiere considerar la experiencia y la actuación como principio y fin de cualquier reflexión (urbana). Como dice Edward de Bono: "pensar es la exploración deliberada de la experiencia con un propósito: entender, decidir planear, resolver problemas, juzgar y actuar". 
Este enfoque detecta en el acontecimiento o la acción, la fuerza central para motivar el entendimiento de la noción del habitar. Es necesario estar en un lugar para actuar y esta actuación valida la existencia consciente. Es este un acercamiento que ha desarrollado ampliamente Claudio Cavelli y que se puede condensar en tres palabras: Estar para Ser. Es evidente que la noción de estar implica entender que tenemos cuerpo y ocupamos espacio, pero a su vez somos seres espaciantes para evolucionar hacia al habitar. La diferencia entre Ocupar y Habitar intentará dilucidarse más adelante.

En este punto parece pertinente intentar sintetizar o re-direccionar la cita de apertura hacia: El lugar orienta a la acción desde el cuerpo emocionado.

Esto podría dar origen a una premisa fundamental para el diseño del espacio público: Es desde el territorio, el paisaje o el lugar como se deben delinear los verbos - o las acciones - que permitan generar acontecimientos que a su vez definan los hábitos o ritos del habitante de la ciudad. Estos hábitos o ritos, individuales o colectivos, son los responsables de edificar una cultura urbana. Ellos no pueden aislarse de un entendimiento del lugar o paisaje contenedor debido a que involucran, necesariamente, un sentimiento desprendido de un cuerpo emocionalmente sensible, dotado físicamente de sentidos o receptores - lectores de datos externos.

\section{2. ¿̇Se puede ser neutral ante el territorio, o es el territorio un elemento neutral?}

Terra Matter: “...pone de manifiesto, en la explicación que hace del universo, que el hombre nunca es un 'sujeto puro' que pasivamente resulta espectador desinteresado de lo que lo rodea y le atañe, ya que la relación que establece con el mundo es siempre significada y por lo tanto se basa en el 'carácter proyectual' de lo que se le presenta..." (Yory García, Mario. Topofilia o la dimensión poética del habitar)

Esta apreciación, la cual refiere a un mito de los bosquimanos Kung del desierto del Kalahari en Botswana, acentúa la idea de la ineludible presión que ejerce el territorio en la comprensión del individuo como habitante. La idea del "sujeto impuro" aduce a la afectación concreta e insalvable que ejerce el entorno inmediato sobre el ser, afectando su comportamiento en el momento de ejecutar cualquier tarea productiva o lúdica. Siempre que el ser se concentra en un trabajo cualquiera, las condiciones externas del lugar lo inducen a un modo de operar específico y es desde este procedimiento particular que proyecta su acontecer. De acuerdo al territorio en el cual mora, o Terra Matter, el hombre planea su acción para así modelar las durezas pre-existentes, especialmente las proporcionadas por las condiciones geográficas, más explícitamente en torno a la topografía y el clima, condicionantes fundamentales del paisaje.

Entender el territorio o enclave natural como el recinto por excelencia donde se contiene la ciudad, parece un enfoque sensato que nos sirve para darle base al postulado que entiende a la misma como una sumatoria de itinerarios espontáneos o diseñados. Estos itinerarios exigen una valoración del paisaje (fragmentos de naturaleza enmarcados) y una consideración del verbo como principal materia prima del acercamiento a la concepción del espacio público.

\section{3. ¿Puede el rito interceder entre la religión y la moral?}

Es sabido que el mito engendra la repetición y que la repetición la costumbre, y que la costumbre el rito y que el rito el dogma, y finalmente la herejía. Cada vez, los actos 
acostumbrados han ido haciéndose, a causa de su invariabilidad, más y más inexorables y típicos hasta adquirir la rigidez obsesiva de un ritual. Hay un estado de fatiga que puede ser delicioso, cuando dejamos de luchar contra ella y la tensión se relaja, induciéndonos al abandono y a la irresponsabilidad- ese momento que puede ser también, según Freud, la hora del lobo, en la que, descuidando la vigilancia de la represión, el inconsciente aflora y desmantela nuestra reserva, la hora de las asociaciones inesperadas, de las emociones ocultas y de lo arcaico. (Saer, Juan José. El río sin orillas)

En la cultura urbana la herejía debe verse como el rompimiento del status quo, el cual se ancla firmemente en la moral colectiva -la suma de códigos sociales aceptados implícitamente por los ciudadanos y que enmarcan la forma y la interacción del ser. La forma define los factores de la apariencia, que involucran la indumentaria y los gestos corporales, más cercanos a la noción de "deberes ciudadanos"; la interacción del ser establece los grados de proximidad y los tipos de acciones con los demás, más cercanos a la noción de "derechos ciudadanos".

Los microclimas y el amoblamiento diseñados en el espacio público pueden ayudar a inducir cambios sustanciales en la manera de vestir y en la expresión del lenguaje corporal. Premeditadamente, desde el diseño se puede adelantar una silenciosa revolución o más bien una evolución cultural tamizada por la aparente inocencia de la lúdica. El juego entendido como factor modificador de comportamientos anquilosados por uno o varios factores, tales como una historia asustadiza, una política represiva, una religión conservadora o una realidad violenta agobiante.

El ritual como celebración colectiva puede llegar a ser obsesivo si nace de fanatismos. El dogma, que es la regla del fanatismo, deviene principalmente de un exceso de poder que patrocina un espacio público excesivamente cargado de representatividad o simbolismos. Estos espacios cívicos están, generalmente, despojados de elementos que otorguen una escala humana intimista. La noción de desolación da cabida a actos con coreografías estructuradas desde objetivos políticos donde el ciudadano es un simple actor de reparto que ocupa un área reducida, necesaria para las cuantificaciones numéricas de las estadísticas gubernamentales.

En estos espacios, los elementos estructurantes son los edificios y no el paisaje, en ellos la idea de naturaleza es erradicada o subordinada bajo patrones geométricos estrictos y axialidades excesivamente remarcadas. El ciudadano no habita el espacio bajo su libre albedrío sino que asume la tarea de un pixel. Es solo una parte minúscula de una imagen que le es imposible reconocer. Cualquier gesto corporal debe registrarse con la rigidez de una acción automática. El itinerario espontáneo es anulado y el deambular se torna en sospecha o desobediencia.

Los ritos ciudadanos son la base de la cultura urbana. Esta se enmarca en la dinámica del mito y es responsable fundamental de la construcción mental que los habitantes y visitantes se hacen de la ciudad.

\section{4. ¿Debería ser reemplazada la escenografía representativa por un "escenario-mirador urbano"?}

Central Park en NY, Copacabana e Ipanama en Río de Janeiro: En sus prácticas, las ciudades y sus habitantes han reubicado lo público en áreas urbanas con claro perfil paisajístico, sustituyendo parcialmente aquellos espacios de representación (plazas) en los que la jerarquización, vigilancia y presencia de un esquema político y policial virtual (o real) significaba una clara segregación social contraria a la libertad ofrecida por un sistema democrático. Está aun por desarrollar una nueva construcción de ob- 
servatorios y foros para la interrelación entre humanos y no humanos que permitan reelaborar la posición del paisajismo hacia una progresiva disolución de la forma presente en el espacio público. (Abalos, Iñaki. Atlas pintoresco)

Cada desarrollo particular de espacio público incide en la construcción futura de la ciudad, es por eso que cualquier acción exige una prefiguración de la fisonomía urbana y una predicción del comportamiento ciudadano. Estas dos imágenes anticipatorias deben estar estrechamente ligadas con la relación (deseada) entre los elementos naturales suministrados por el enclave geográfico original -que aun sobrevive a la urbanización- las preexistencias sociales y las aspiraciones culturales.

El espacio público se valida construyendo una completa redescripción del lugar. Ante todo, proponiendo la invención de una topografía que permita el libre deambular por múltiples circuitos -donde se podría decir que confluyen montañas, mesetas, acantilados, laderas, planicies, playas, agua, árboles, flores, jardines, muelles, malecones, miradores, galerías, patios, puentes y pérgolas- produciendo un doble movimiento, desde el proyecto a la naturaleza y viceversa, y verificando el concepto de "ciudad-paisaje", el cual supera cualquier argumento de oportunidad política de connotaciones retóricas negativas del poder.

En la actualidad, muchos de los edificios públicos que circundan los espacios públicos siguen perpetuando una política impositiva y autoritaria, una relación tajante entre el exterior y el interior, actuando como vallas contenedoras de la masa colectiva; estos renuncian a brindar unos deambulatorios vestibulares que sirven de umbrales escampados para "paisajear" libremente como espectador, a través de las rutas de sombra sin ningún rol impuesto. Una importante experiencia de arquitectura en el verdadero sentido urbano.

Los nuevos programas institucionales y comerciales se deben adosar a las plataformas de los edificios públicos para operar como zócalos urbanos activos que ablandan las desafiantes superficies ciegas. Se debe plantear también la disolución o progresiva invisibilidad de los edificios para lograr dar una continuidad natural al basamento y garantizar la movilidad peatonal. Las cubiertas además deben estar pensadas de tal forma que permitan una circulación ininterrumpida por "encima" de la ciudad. Es fundamental acercarse a una condición híbrida y mestiza, que da paso a una revaloración del paisaje abarcando rasgos territoriales. Buscar llegar a una tipología donde técnica, naturaleza y arquitectura interactúan para intensificar y ampliar el diálogo con el medio físico. El proyecto, entonces, queda resaltado como un instrumento pedagógico que ayuda a comprender los vínculos entre lo construido y el paisaje y su evolución en el tiempo, una exigencia de la condición monumental contemporánea.

El acontecimiento establecido no puede ser otro que el de una comunión entre lugar e individuo; ver y ser visto por la ciudad. Se debe entender a estos vínculos como el resultado más sublime de lo urbano y, además, buscar un aporte de lo memorable.

Dilucidando en base a los argumentos anteriores se puede inferir que el espacio cívico podría ser pensado también como el lugar donde se acaba la ciudad y empieza el cielo, en donde encalla el agua, brota una cordillera o florece un bosque. Un alto en el camino del acelerado desplazamiento programado del ciudadano productivo. Un observatorio que le ayude a orientarse y centrarse en sí mismo como individuo; un lugar que le sirva para entenderse o explicarse como parte de un todo y donde el paisaje sirva como elemento distintivo. El carácter de los ciudadanos está forjado fuertemente por los paralelos "territorio-clima" y "ciudad-paisaje". 


\section{5. ¿Puede un lugar prevalecer sin la memoria del evento?}

No se puede dar la especificidad sin la memoria, ni memoria que no provenga de la especifidad, y es el acontecimiento que permite la construcción de la relación del hombre con la ciudad permitiéndole reconocerse como de un lugar, de una cultura. Esto implica forzosamente la conjunción entre espacios singulares, (generalmente públicos o al menos de acceso público durante la celebración) y acontecimientos relevantes y periódicos. Constituyen habitualmente hitos en los que fundamenta la imagen urbana y el carácter distintivo de una ciudad, tanto para los residentes y visitantes. Aquí radica la importancia de la existencia de los 'Event Places': lugares con acontecimientos asociados como elemento fundamental de la promoción de las ciudades (PamplonaSan Fermín, El Palio-Siena, Río de Janeiro-carnaval). (Moisset, Inés y Paris, Omar. Hipótesis de paisaje)

El vacío estructurado permite el evento de fuerte recordación (o identidad), sin necesidad del acontecimiento de gran escala. Este vacío estructurado es la pieza clave para el verdadero espacio cívico que construye memoria urbana, que luego se convierte en cultura ciudadana o civilidad. Este se comporta muy diferente a un espacio residual desarticulado, que no opera como receptáculo de ningún acontecimiento singular, ya sea individual o colectivo.

El itinerario de un transeúnte no es más que una partitura acompasada por medio de pausas y acentos, la acción y la contemplación como complementos indisociables. El silencio premeditado se hace indispensable en el momento de exponer elementos cargados de carácter o significación: bordeando un elemento visual y físicamente muy potente debe haber un área anónima importante, un problema de positivo y negativo. El manejo de la pausa es el verdadero reto del diseñador urbano, comprendiendo primero que la pausa es validada solamente por la acción.

Lidiar con un gran espacio abierto, "vacío", produce una profunda experiencia; inicialmente paralizadora, luego conmovedora. Un "claro en el bosque" siempre condicionará el espíritu de su descubridor, predisponiéndolo a un evento extraordinario. Históricamente estos claros han servido como lugares de ritos y magia, plataformas de comunicación con un mas allá. Esta ausencia de techo abre una conexión espiritual e invita a lo colectivo. Este sentirse expuesto al escrutinio, en medio del vacío, acciona la noción de moral -como código de comportamiento social-precipitando el uso virtual de la máscara. La "amenaza" de un encuentro con el otro y no de un verdadero encuentro resulta en pura tensión, esta expectación es el motor dinámico del posible evento.

Este entrabe, o relación inseparable entre el vacío urbano y el acontecimiento, constituye la noción del evento urbano como paisaje en movimiento.

\section{6. ¿El carácter de lo temático agudiza la asociación?}

Las asociaciones son producto de las emociones, de los recuerdos; nacen de nuestros pensamientos personales y son parte de las imágenes y los recuerdos de la cultura a la que pertenecemos. El mundo de las asociaciones es dinámico y, a veces, tenemos que deshacernos de antiguas asociaciones y adaptarnos a las nuevas. En este caso tenemos que disociar. Todavía actuamos como gente que se fía de una silla o de una mesa solo cuando podemos ver claramente que estos objetos tienen patas de animales, elementos 
todavía no disociados. Hay sillas que son la expresión escultural de una invitación. Siéntate, parecen decir. Su gesto sugieren relajación, y lo asociamos con un abrazo, con el gesto de la madre que coge al niño en su regazo. (Beljon, J. J. Gramática del arte)

Son las asociaciones las responsables de crear las relaciones emotivas del usuario con los espacios cívicos. Este acercamiento inicial del ciudadano se debe producir por afinidades y convicciones más que por imposiciones; es aquí donde toma importancia la noción de cluster: una aglomeración en apariencia aleatoria, de elementos más o menos de la misma forma y escala, que comparten algunos rasgos. Este concepto debe alcanzar a las configuraciones y agrupaciones de muebles, que no se trate de una colección de los mismos sino de la creación de una atmósfera -o de un carácter específicodentro de un área más vasta, una especie de microclima que dé escala al recinto general y permita la noción de habitabilidad.

Estos clusters deben estar apoyados en programas temáticos cotidianos (tales como la lectura del periódico o el tomar el sol) o extraordinarios (como el acostarse a ver las estrellas). Solo así pueden garantizar unas apropiaciones espontáneas (muchas de las cuales deben haber sido pre-visualizadas), sin la necesidad de eventos multitudinarios programados.

Las intenciones de utilización del espacio cívico, por parte de los posibles usuarios, deben estar meticulosamente estudiadas. Para direccionar estas acciones, el mobiliario urbano resulta un instrumento privilegiado; es desde el mismo que el cuerpo inicia una interacción con el espacio público.

La multiplicidad escalar, la variedad proporcional, las perspectivas vinculantes, la manipulación instrumental del material vegetal y la anti-tipología del mobiliario, son todas estrategias de diseño indispensables para provocar asociaciones inesperadas en el usuario, pero intuidas -todo lo posible- por el proyectista. Los elementos resultantes de estos factores, más el complemento esencial del usuario, constituyen la materia prima para la construcción de una cultura urbana.

\section{7. ¿̇e puede pensar un espacio cívico sin tener en cuenta los condicionantes naturales del clima?} Es interesante insistir en un criterio muy poco discutido dentro de las definiciones del paisaje: el clima como el agente activo o "el paisaje en acción". Pareciera que casi siempre se le discute como objeto de contemplación, un sustantivo pasivo o tema de composición: formas, trazos y manchas. La distancia con que se mira normalmente al proyecto urbano elimina accidentes y rugosidades, resolviendo todo en geometría. Este desprendimiento virtual del territorio aísla al diseñador urbano de la realidad atmosférica integral y asume al hombre como un ente abstracto e indiferente, el cual ocupará una cartografía conceptual o idealista, ajena a los condicionamientos concretos del territorio.

La cuantificación técnica y la composición artística requieren de ocupantes y no de habitantes con vínculos emocionales y por ende sensibles.

El clima es un factor del paisaje que condiciona especialmente e influye en la construcción y definición de la morfología de los espacios de la ciudad. Puede entonces fortalecerse la idea de una necesidad de "manipulación consciente" de ciertos factores climáticos, por medio de elementos arquitectónicos: "diseñar el clima", como herramienta fundamental del paisajismo.

\section{8. ¿Es la permanencia un factor decisivo para la convivencia?}

Para saber si una casa es o no buena arquitectura, hay que preguntárselo a sus habitantes, sobretodo si son gente normal sin manías esnobs; si dicen que viven muy 
cómodos, la casa no debe tener ningún interés; si dicen que viven mal, es posible que sea una buena pieza de arquitectura... (Saenz de Oiza, Javier citado por Oriol Bohigas en Contra la incontinencia urbana)

La idea de que el objeto bien diseñado no tiene relación con el confort de quien lo utiliza o experimenta ha sido adoptada profundamente por muchos arquitectos que renuncian a aceptar la necesidad de un equilibrio entre la satisfacción del usuario y la calidad artística de una obra. La consonancia que atañe a los sentimientos y a la empatía es un factor determinante en la adopción de la forma, material y espiritual.

El mobiliario urbano resulta un atractor natural en la aproximación del usuario al espacio público y tiene la responsabilidad de suscitar una interacción que resulte grata y estimulante. La placidez es un estado que permite, sin esfuerzo, permanecer extendidamente en un lugar. Es una condición indispensable para el "sedentarismo urbano". Para ello debe estar presente, como criterio fundamental, la noción de confort, entendido como la "medición del bienestar" y experimentado en la comprobación real y funcional del mueble.

Esta es una instancia clave en la iniciación de un acercamiento amigable o sugestivo que le permitirá al habitante ahondar en estancias más espirituales, reflexivas o celebratorias. Según algunos conceptos filosóficos del yoga, cuando un ser permite que todo el mundo fluya hacia él y él hacia todo el mundo, se está celebrando la vida; la celebración, por su parte, se entiende como la cumbre de la meditación, una fluidez solamente posible en medio de una condición de felicidad. El estado de éxtasis debe ser una premisa muy importante en el momento de pensar la arquitectura urbana, en todas sus escalas.

Otro aspecto fundamental a considerar en los sistemas de amoblamiento, dentro de la noción de confort, es la gradación como escala de valores. La jerarquía, más que establecerse como factor impositivo, se convierte en un elemento que permite un juicio diferenciador por parte del usuario, otorgándole libertad y facilitando una consonancia entre "operador" y "aparato". Esta afinidad posibilita una interactividad exigente de re-creación o imaginación, un estado ideal de soñar despierto, una condición de escapismo que libera al ciudadano de sus cargas cotidianas y lo induce a una condición de autonomía. El paso (o evolución) de un ser autómata -una especie de pasajero urbano condicionado inconscientemente por las dinámicas del intercambio productivo- a un ser consciente y conductor de su devenir inmediato; un presente vivaz sin agobio de futuro.

\section{9. ¿Es posible desconocer la acción en la seducción de la forma?}

"La forma es un fenómeno que despierta los recursos supremos de nuestra integralidad y proporciona los medios que hechizan nuestra sensibilidad e incluso pueden seducirnos hasta el borde del delirio". (M. Dalcq, profesor de Anatomía y Embriología en la Universidad de Bruselas)

El diseño del mobiliario debe abordarse como la fabricación de un instrumento musical que busca esencialmente poseer los medios necesarios para sonar de una forma particular, con una indiferencia por la apariencia resultante del mismo. Este método se aparta de una formalización a priori basada en nociones academicistas que privilegian las estrategias de composición geométrica. La formalización a priori conlleva fácilmente a una pérdida de la capacidad conductora del objeto por desestimar 
la acción. Este tipo de acercamiento proyectual es simplista desde el punto de vista antropológico, ya que confía en exceso de la capacidad visual del usuario, permitiendo un juzgamiento solamente apoyado en la noción de belleza, el gusto como valor socio-cultural. Es por medio de este enfoque extremadamente formalista que muchos de los espacios públicos contemporáneos entran en desuso o abuso rápidamente, ya que aparentemente exigen "una educación estética previa del usuario".

Este argumento no es plausible desde ningún punto de vista ya que el ciudadano debe estar exento de la necesidad de un adiestramiento artístico específico para poder disfrutar de su libertad lúdicoexpresiva; de ser así estaríamos ante un caso de tiranía del arte que abortaría cualquier noción democrática del espacio público.

Cuando se aborda el tema del diseño del mobiliario público es apremiante entender que es a través del uso que surge el entendimiento de las posibilidades liberadoras de un comportamiento específico.

Entender al mobiliario urbano como un grupo de objetos bellos de catálogo dispuestos lógicamente sobre el espacio público no puede sino conducir a una anulación de la re-creación permanente de la cultura urbana. Esta cultura solo puede darse desde el aporte individual que incide en el comportamiento grupal. Por lo general las (grandes) reacciones colectivas están acompañadas de una carga de violencia que se genera en la no-conciencia de un ser autómata, una especie de accionar en estampida.

En cambio, del estado emocionado se desprende una sensación de eternidad; se experimenta una clase de inmortalidad sedante que descomprime las tensiones acumuladas de hábitos insulsos de la realidad. Si bien el sistema de amoblamiento opera por jerarquía, cada objeto debe poseer un punto focal donde se concentre la tensión necesaria para despertar el interés. La contradicción como desafío a la gravedad, la invisibilidad como desdén de la tipología, la continuidad como anulación de la suma de las partes, son todos enfoques estratégicos que suscitan, a través de la curiosidad, un acercamiento emotivo. Esta tentación es la primera fase de una reactivación perceptiva; luego, de manera más profunda, se concreta una fase de concientización, cuando el usuario-operador es consciente de que acaba de "descubrir" un nuevo modus operandi, y la condición de autor eleva el espíritu afianzando la autoestima, dando lugar al ego y a la individualidad. De este modo se supera el rol de obediente operador colectivo.

Rescatar la individualidad, condición de verdadera libertad, es uno de los deberes más apremiantes del espacio cívico.

\section{0. ¿Son viables las relecturas sin la abstracción?}

"La síntesis se alcanza por medio del assemblage y del collage. Encuentras un objeto (objet trouve), luego encuentras otro que parece contradecir al primero. Los juntas. El resultado es algo nuevo, fresco, coherencia donde primero parecía haber caos". (Beljon, J.J. Gramática del arte)

En el diseño del mobiliario público la reducción es una herramienta fundamental ya que implica concentrarse en lo rigurosamente importante: la acción. No se trata de desdibujar los contornos de un objeto, sino de aumentar su expresión obviando choques visuales a favor de un resultado más impactante; menos palabras para decir más.

Por consiguiente, un aspecto bien delicado es definir la carga lúdica y referencial del mueble sin sobrecargarlo de complejidad o citas evidentes como es el caso de muchos follies. Por medio de una síntesis formal se incentivan las conexiones mentales y físicas en el usuario; se abre paso al arte de la implica- 
ción: mostrar solamente una parte de algo con el fin de despertar la curiosidad del espectador para conocer el resto; este hecho aumenta el dinamismo del usuario y la ciudad se hace más vital, más ligera y menos fatigosa. La soportable levedad urbana, tan necesaria en las crecientes y asfixiantes metrópolis. Esta implicación es aun más amplia que lo que representa la expresión pars pro toto que significa la parte por el todo: que sea la imaginación del usuario la que "complete" el significado del objeto urbano.

\section{1. ¿Es practicable la arquitectura pública sin cliente?}

Las personas que comparten los espacios públicos son sólo masas corpóreas, perfiles que han renunciado voluntariamente a toda o a gran parte de su identidad. Han logrado con ello colocarse por encima de toda cosificación, lo que implica que encarnan una especie de cualquiera en general, $\mathrm{o}$, si se prefiere, un todos en particular, que hace bueno el principio interaccionista de que en una sociedad como la nuestra la figura que domina es la del otro generalizado. En la experiencia del espacio público ese otro generalizado ni siquiera es otro concreto, sino otro difuso, sin rostro -puesto que reúne todos los rostros-, acaso tan sólo un amasijo de reflejos y estallidos glaúquicos. (Delgado, Manuel. Anonimato y ciudadanía)

El transeúnte desconocido, personaje al mismo tiempo vulgar y misterioso que es el hombre o la mujer de la multitud, es la materia prima para definir las estrategias de diseño. Es desde su individualidad que mejor opera su relación con el espacio público.

Cuando se desarrolla un proyecto de espacio o de amoblamiento público se puede optar por dos caminos: el de la participación, donde los clientes son algunos ciudadanos de la comunidad, o el de la interpretación, donde el cliente es un constructo mental. La experiencia en muchos casos ha demostrado darle la razón al siguiente argumento de Oscar Wilde: la opinión pública solo existe donde no existen las ideas.

La opinión pública tiende a buscar una satisfacción inmediata con una experiencia a corto plazo. Pero se debe tener cuidado de no abusar de la "instantaneidad": por su intensidad se corre el riesgo de una saturación sensitiva y de la posible desaparición inmediata del interés. Es evidente que esto puede ocurrir por el abuso indiscriminado de mecanismos sobre-estimulantes o sobre-diseñados. Equipamientos públicos que aniquilan la reinterpretación por estar sobrecargados de semántica o sintaxis, llegando a ser tan efectivos en una experiencia de choque que anulan una posterior etapa de reflexión y meditación, pasos necesarios para el verdadero goce espiritual profundo que da lugar a lo aspiracional.

Un dispositivo diseñado para provocar fuertes experiencias físicas, acelerando los procesos naturales y espontáneos, puede alcanzar a divertir solo un instante, inhibiendo el verdadero sentido de la re-creación, que debe ser prolongada por un estado de auto-inducción. De la misma forma que un espacio vacío residual, ausente de significado y diseño, acaba por evitar su aprovechamiento como lugar de acontecimiento.

Oriol Bohigas, en su libro Contra la incontinencia urbana, recuerda una "divertida" expresión de un arquitecto italiano de su generación: "Hacer arquitectura sin tener cliente es impracticable, pero hacer buena arquitectura teniendo un cliente es imposible". Este argumento no tiene cabida cuando se piensa la ciudad; es un concepto nacido de la práctica privada elitista, que por demasiado tiempo ha prevalecido en los códigos de práctica de un gran número de arquitectos. De nuevo, una distor- 
sionada herencia de algunos de los maestros modernos ha atentado contra la idea del "diseño para la gente", objetivo principal del proyecto urbano. Este criterio no se puede confundir con la complacencia sin riesgos. El proyecto de espacio público debe ser siempre una investigación abierta sobre el comportamiento humano en sociedad, una especie de experimento de formulación de nuevas actitudes. La arquitectura es a la cultura urbana lo que el encofrado es al hormigón armado, una estancia temporal para lo más perenne y valioso de un asentamiento humano: su civilidad.

Bohigas afirma que la arquitectura además de un arte es un servicio directo a la sociedad, aquella sociedad que no comprende ni desea la anticipación de unas nuevas formas de habitabilidad o unos nuevos programas estéticos y no está demasiado dispuesta al papel de conejillo de indias ni, por otra parte, a pagar la experiencia arriesgada.

\section{2. ¿Es la fricción (o interacción) un concepto indispensable para la formulación del espacio público?}

Muchos de los espacios públicos asumen la calle o calles que los enmarcan como vacío. La inexistencia de dispositivos de interacción y el trazo de senderos rígidos promueven una no-interacción; invitan a una especie de visita ligera con connotaciones de asepsia (cuando el peatón se desplaza a través de andenes atiborrados de gente y con amoblamiento mal ubicado, aumenta la velocidad de su paso). La plaza y el parque, por otro lado, son generalmente pensados para ser vistos; el diseño se fundamenta en lo sustantivo y no en el verbo, en la acción o el acontecimiento humano. Estos espacios están compuestos bajo el absoluto rigor de una geometría totalizadora, nacida del concepto de "cruzar o atravesar" y no de "permanencia".

Esta situación de movilidad acelerada atenta contra la estancia desprevenida de los usuarios de este espacio cívico, desincentivando la permanencia individual y el acontecimiento colectivo. Ascender y descender por rampas o escaleras es una estrategia que asegura la desaceleración de estos ritmos desorbitados. La plataforma, un dispositivo urbano muy arraigado en la arquitectura pre-hispánica mesoamericana, tiene la connotación de exaltación, de elevación, condición ideal para obtener miradores naturales. Estos planos escalonados hacen oscilar permanentemente al visitante entre la condición de espectador y de actor, ver y ser visto.

Las gradas -asientos naturales del espacio público- y los planos inclinados -los lugares naturales para recostarse- ambos proporcionan al usuario un estado ergonómico que combina la posibilidad del estarse alerta con una sensación de tranquilidad: el estado pasivo de observación está complementado con la facilidad e inmediatez de ponerse de pie, reacción defensiva instintiva. Esta idea de protección que prestan las plataformas conseguidas con gradas y rampas, permite al usuario permanecer, estarse en un lugar.

Bajo una aproximación filosófica, es indispensable Estar para poder Ser, pertenecer para luego trascender.

Además de las plataformas o recintos caracterizados, el amoblamiento debe suplir las demandas de la pausa. El descanso es una de las necesidades más apremiantes del cuerpo en la utilización del espacio cívico. Después de suplidas las necesidades básicas, el transeúnte puede adoptar un comportamiento más sedentario que lo puede inducir a la interacción social, a la posibilidad de compartir un rito colectivo.

Generalmente se ha aceptado, sin mucho cuestionamiento, que la plaza es un ensanchamiento de la calle, por lo que se ha obviado la existencia de observatorios, escenarios o plataformas. Esto es en gran medida lo que explica la inoperancia de las plazas y los parques heredados de los periodos colo- 
nial y republicano, o los espacios públicos contemporáneos diseñados bajo esta lógica funcionalista. En la construcción del espacio cívico participativo la interacción es un factor crucial del diseño, el usuario es parte activa del diseño cambiante del espacio.

En las concepciones historicistas, el ciudadano no hace parte del paisaje sino que se limita a contemplarlo. Hoy es fundamental entender que esas "manchas de colores temporarias" (los visitantes) son materia prima para pensar el espacio cívico y son parte esencial del paisaje urbano. Estas "manchas activadas de transeúntes" constituyen lo orgánico y lo cambiante, se podría decir: lo más parecido a la naturaleza dentro del proyecto urbano, aun más que el uso del material vegetal, que es más predecible.

\section{3. ¿Es lo inesperado una política eficaz en la búsqueda de la equidad y la dignidad ciudadanas?}

"La caridad degrada y desmoraliza... la caridad crea una multitud de pecados. A los ojos del pensador, el verdadero daño que causa la compasión emotiva es que limita el conocimiento, y por eso nos impide resolver cualquier problema social". (Wilde, Oscar. Aforismos y paradojas)

El afán de cumplir con la necesidad apremiante opera como un paralizador de aspiraciones empujando el diseño urbano a resoluciones desprovistas de toda interpretación. La inclusión debe trascender la posibilidad de que todos "quepan" o que puedan ocupar el espacio, para acceder a la posibilidad de que todos "habiten". Esto significa dejar de lado actividades autómatas o costumbres inconscientes que den paso a unos ritos conscientes.

La re-creación se da a través de la presencia de elementos inesperados; en cambio, las soluciones sin carácter vienen de una noción nociva de caridad, la cual se limita a aprovisionar con apenas lo justo a unas necesidades apremiantes. El valor pedagógico y la equidad son desestimados en estas "soluciones-máquinas", extremadamente descaracterizadas y que socialmente solo cumplen con requisitos cuantitativos. Estas se limitan a suplir un déficit estadístico de la responsabilidad estatal o del derecho ciudadano: el metro cuadrado por habitante parece ser la valoración principal. Lo fácilmente reconocible orienta la formalización de sus elementos y hace aflorar una actitud bucólica que empuja hacia soluciones figurativas complacientes y reduccionistas, las cuales anulan cualquier posibilidad de aspiración.

Tanto el espacio público colectivo como su amoblamiento deben, por medio de la abstracción, apartarse de un código figurativo reconocible para que el condicionamiento utilitario pueda posicionarse dentro de una red de posibilidades. Deben desaparecer los rastros de un estudio ergonómico conductivista preliminar que paraliza al usuario en un trabajo o una acción en particular, para permitirle al mismo actuar según las exigencias del momento inmediato. Este nuevo usuario se expande entonces sin necesidad de desarrollar vínculos duraderos con nada, incluyendo sus propias re-creaciones, y permitiendo, a través de un comportamiento impredecible, su dominación sobre el espacio. Esta abstracción sirve de estímulo para la emancipación ciudadana y permite una expectativa permanente dirigida hacia lo insólito, factor fundamental para desdibujar las líneas que definen la noción de "necesidad-caridad".

Esta posibilidad facilitadora de los instrumentos públicos consigue que los usuarios experimenten una verdadera noción de libertad creadora o re-creadora; la imaginación y la velocidad de actuación les permite moverse a su antojo con una falta de compromiso y una efusividad tales que les facilita 
aparecer y desaparecer en cualquier momento. $\mathrm{Si}$ a las personas se les permite que se muevan y actúen más rápido, son ellas las dominantes y no el espacio público.

Los niños son, por su capacidad de re-creación y su velocidad de adaptación, los actores principales de esta transformación contemporánea del espacio civil, lúdico y educador; son ellos quienes parecen vivir más cómodos en esta época fluida de cambios constantes, de información global y mundos virtuales.

El libre albedrío se asocia con la cercanía a la incertidumbre, instancia bajo la cual las personas consiguen mantener sus actos en libertad.

\section{4. ¿En la cultura urbana puede ser más importante lo implícito que lo explicito?}

La competencia es la capacidad virtual de producir y comprender un número infinito de enunciados, así como de manejar una cantidad no menos indeterminada de códigos. Se trata de un saber, una facultad potencialidad latente previa a la acción y requisito para ella. Por lo tanto es fundamental estudiar y comprender las normas psicológicas, sociales y culturales que están presupuestas en un acto de comunicación espontáneo del transeúnte desprevenido. Conocer o intuir las pautas que ordenan en secreto estas relaciones ocasionales es indispensable... (Delgado, Manuel. Anonimato y ciudadanía)

El "sentido común" atañe a la posibilidad que posee un individuo de renunciar a intentar cambiar las reglas del medio, para adaptarse a ellas. Esta actitud implica una noción de moral; de lo correcto. En el espacio público lo postural es un lenguaje categórico que exterioriza los preceptos morales del individuo. Es entonces desde la forma que adopta el cuerpo que pueden desprenderse nuevas actitudes de comportamiento, las cuales pueden romper con tabúes sociales definidos por estándares éticos anacrónicos que no permiten la evolución de conceptos contemporáneos de convivencia. La acumulación y reiteración de estos movimientos corporales se van convirtiendo en los rasgos de la memoria colectiva para dar paso a una nueva cultura urbana.

El modesto contorneo del cuerpo es un acto profundamente lírico, una forma de escritura en que cada trayecto que traza es un relato, una historia íntima, un tejer sosegado de memoria que convierte el actor en autor. De este modo se reescribe la experiencia urbana como construcción cultural, desde un encofrado predispuesto para ello, superando, claro, cualquier predicción de comportamiento.

$\mathrm{Al}$ respecto, Manuel Delgado dice "El lenguaje corporal se utiliza como una acción que se desarrolla con fines prácticos de cooperación entre individuos que han de compartir un mismo escenario. Cada acontecimiento público específico requiere una actitud o gesto de socialización de los co-participantes, tarea que los actores aprenden con más eficacia si el espacio público y su amoblamiento están predispuestos correctamente".

Los transeúntes o deambuladores urbanos van trazando diagramas aparentemente espontáneos o caprichosos que tienen incorporadas nociones de cooperación autorregulada por un consenso implícito y no por coacción, pero sí potencializada por una predisposición estudiada. Para canalizar o dirigir estas acciones de movilidad del transeúnte, una herramienta que resulta valiosísima son los diagramas de "pasos perdidos": mapas que se trazan intuyendo los posibles recorridos según los focos de emisión de público y la posible atracción del sujeto hacia elementos del espacio público, especialmente el mobiliario. Estas líneas punteadas registran un contorneo natural que simula el fluir 
de un líquido en descenso pausado y sirve para evitar turbulencias innecesarias, pero sin perder la capacidad de fricción.

\section{5. ¿El exceso de ornamentación puede inhibir la actuación del usuario?}

La participación se produce en términos de papel o rol, que es la manera de indicar como cada elemento copresente negocia su relación con los demás a partir de un uso diferenciado de los recursos con los que cuenta. Esta idea de rol es fundamental, pues se opone a la de status que caracterizaba las relaciones sociales en las sociedades tradicionales no urbanizadas, que servia para indicar una serie de derechos y deberes claramente definidos e inmutables, que cada cual recibía en su nacimiento en un lugar u otro de la estructura social". (Delgado, Manuel. Anonimato y ciudadanía)

La ornamentación en el mobiliario presenta un riesgo, ya que precipita juicios de valor estilísticos necesariamente asociados con una cultura socio-económica que induce a aspectos morales del comportamiento y que acentúa la diferencia social de la población en forma negativa. Esta especie de segregación estilística posee además una carga bucólica del pasado que interfiere con la reinvención o auto-regeneración de la ciudad, una condición de adaptabilidad indispensable para la ciudad contemporánea.

La ciudad es un ente vivo que sin duda puede verse desde una perspectiva evolucionista y que, al igual que un organismo, produce mutaciones en forma natural.

El espacio público se debe plantear como una analogía de la arquitectura en el tiempo y en el lugar. Un gran anfiteatro para la celebración de lo público, primer y gran cometido de la arquitectura urbana. La participación del ciudadano en estos espacios, a manera de rol, da una relación en particular que teje una urdimbre de significados, los cuales hacen inseparable lo físico de lo eventual.

Esto valida la afirmación de Jean Genet acerca de que la arquitectura del teatro debe ser descubierta: un recinto a cielo abierto, una especie de observatorio situado entre lo extraño y lo cotidiano, que deje entrever un paisaje inesperado; una geografía de la ciudad que aflora casi desconocida y articula un sistema de escenarios aptos para albergar múltiples acontecimientos simultáneos, o un "gran evento home-less", que lleva deambulando mucho tiempo sin la complicidad de un receptáculo propicio. Adecuar una infraestructura urbana para este y otros eventos asociados permite dotar de expresión a los valores colectivos emergentes de la sociedad, condición esencial de las libertades democráticas (tan necesarias en la construcción de un referente cultural permanente).

La idea de la ciudad como museo o como escenografía permanente y como alternativa políticoeconómica (o atracción para el turista), exige ver a los elementos urbanos desde un enfoque taxidérmico: un ser privado de vida que se conserva artificialmente. Este proceso exige de unos "curadores cultos" que necesariamente imponen una visión sesgada de status acorde con la alcurnia que se le quiere imponer a la ciudad. En este sentido, la ciudad se puede concebir como una construcción artificial impuesta, pero nada más apartado de su realidad cambiante, compuesta por capas antropológicas y arqueológicas sucesivas que sirven de matriz para una "imagen mental" que supera el contenedor de donde se genera.

La ciudad no difiere de la naturaleza y sus fuerzas de crecimiento y cambio permanente; sin embargo, se trata de una construcción racional medida por imágenes mentales fragmentadas. La ciudadpaisaje está articulada y compuesta por la mirada de varios autores, ciudadanos y extranjeros. Es un 
retrato colectivo siempre inacabado, que sirve de testimonio de la relación existente entre el enclave natural original y la forma del asentamiento de la polis.

\section{6. ¿Es el lenguaje corporal el instrumento de comunicación más eficaz para la convivencia ciu- dadana?}

La tiesura registrada en el cuerpo, con que se pueden sentar los habitantes en un parque, puede ser un fiel reflejo del acartonamiento social o el estado de alerta de sus ciudadanos ante la noción de inseguridad. Al ver un cuerpo desparramado plácidamente, mirando las estrellas, en un parque de Medellín, queda imposible concluir que, hasta hace unos años, esta fue una de las ciudades más violentas del planeta. Pero si se puede deducir que sus habitantes están volviéndose conscientes de la relación con el lugar y el paisaje de la ciudad. Este registro físico o muscular, imprime en la memoria del usuario una noción creíble de seguridad y esta placidez emite un código de desarme que genera un optimismo constructivo; este cuerpo desgonzado permite tanto una lectura desde el interior del individuo como del interior del espectador; esta mirada de la realidad desde el cuerpo emocionado induce cambios mucho más instantáneos que cualquier discurso racional. En este contexto, parece muy válido el precepto de aprender a escuchar lo que vemos.

Miramos y aprendemos también con el cuerpo, siempre más desobediente que la razón, pero al que se puede engañar menos fácilmente.

Se puede afirmar que el rito y el acontecimiento urbano implican una secuencia de acciones que involucran necesariamente al cuerpo (objeto ergonómico medible) y que sus partes distan mucho de ser medidas en metros. Por consiguiente, el urbanismo es un problema de milímetros y es desde el mobiliario y el espacio público que lo alberga, que se orienta la acción del cuerpo emocionado; para afianzar una relación afectiva con el paisaje desde y hacia la ciudad.

\section{7. ¿La agrupación del mobiliario puede operar como itinerario virtual?}

La movilidad peatonal obliga a establecer un equilibrio entre la fluidez de los desplazamientos obligados y los elegidos. Es necesario disponer y entender los objetos del mobiliario como protuberancias sobre la superficie, los cuales ofrecen cierta resistencia a los flujos acelerados; turbulencias delicadas que no alcancen a taponar estas corrientes encausadas de transeúntes. Visualizar estas aglomeraciones peatonales en movimiento, como flujos laminares de agua, ayuda a manipular su aceleración o desaceleración bajo lógicas de presión, controlando un represamiento innecesario y contraproducente.

En el espacio público, lo que importa es el camino que traza el habitante, no su destino. La línea, distancia más corta entre dos puntos no debe ser una premisa, por el contrario el zigzaguear, serpentear y deambular debe ser estimulado. Estas rutas físicas que se convierten en construcciones mentales son la base de una memoria urbana y de una imagen de ciudad-paisaje propia.

La manera de agrupar el amoblamiento tiene enorme incidencia en el momento de definir el direccionamiento de flujos peatonales, superficies de texturas cambiantes, focos de actividad, relaciones interpersonales, cadenas de acontecimientos programáticos y la relimitación virtual para eventos.

Esto requiere de estrategias conscientes que se aparten de los tecnicismos establecidos por los manuales de espacio público y busquen asociaciones y relaciones con un entorno más amplio, que involucren también la geografía como elemento de orientación e identidad; perspectivas vinculantes que enlacen itinerarios previstos sin una conexión directa, metas de desplazamiento sin la necesidad de ejes conectores directos o explícitos; rutas mentales que permitan un deambular más errático y 
posibiliten el "perderse momentáneamente", condición necesaria para redescubrir la ciudad y sorprenderse con ella.

\section{8. ¿Cómo garantizar el efecto detonante de un proyecto urbano?}

El movimiento en la ciudad es indispensable para ir al trabajo, aprovisionarse, divertirse, curarse; el desplazamiento es un elemento cada vez más importante en la vida de los individuos y de las colectividades. Poder desplazarse se ha convertido en eso que podríamos llamar un 'derecho genérico', es decir una condición necesaria para acceder a los otros derechos. Con demasiada frecuencia todavía las infraestructuras del transporte y espacio público están concebidas en función de lógicas técnicas estrechas. El nuevo contexto socio-espacial obliga a los arquitectos, a los desarrollistas, a los transportistas y a los urbanistas a renovar sus conceptos, sus herramientas y sus proyectos". (Francois Ascher, presidente del concejo científico Institut pour la ville en mouvement y profesor del Instituto Francés de Urbanismo)

Si se miran con detenimiento las infraestructuras de transporte y el equipamiento urbano, se puede conocer con bastante aproximación de donde viene y hacia donde va la gente dentro del casco urbano. De esta forma se puede establecer una red lógica de continuidades y flujos que orientan la intervención pública hacia una noción de "acupuntura urbana", dentro de lo que podría ser una estrategia de constelación: conexión entre focos de actividad por medio de infraestructuras existentes pero que denoten una relectura integral de la ciudad, auspiciando un desplazamiento completo a través de la misma y evitando nuevas centralidades autónomas que contribuyan a la segregación espacial.

Para que el espacio público opere como conector de redes peatonales -y no como foco de flujos discontinuos- el proyecto urbano debe pensarse como un nodo detonante de actividad, dentro de la cadena de acontecimientos que se desarrollan en la ciudad. Con la discontinuidad, en cambio, el recinto "vaciado" pasa a ser un espacio abandonado que exige una vigilancia permanente por parte del transeúnte; esta circunstancia torna el recinto cívico en un elemento opresor y dominante, eliminando toda posibilidad de disfrute. En lugar de permitir una mirada centrífuga esto exige una centrípeta; anula la posibilidad de que el espacio cumpla una función de observatorio y proporcione perspectivas vinculantes que amalgaman o entrelazan otros referentes orientadores urbanos o naturales.

\section{9 ¿Es posible evitar la sensación de desarraigo en el vacío urbano?}

Una de las dificultades mayores respecto al espacio público, es definir la escala apropiada del mobiliario para domar o apaciguar lo que puede llamarse la "inmensidad desorientativa" del gran espacio abierto. Son los sistemas vegetales y del mobiliario los responsables de otorgar la escala adecuada que despierte en el usuario un sentimiento de afinidad y evite el de desorientación. Si esta experiencia es negativa puede conducir a una sensación de desarraigo muy propensa a generar una actitud de rechazo y abandono, ya que el usuario puede llegar a considerar que no se le tuvo en cuenta en la concepción del recinto. Que un espacio público resulte extraño y sospechoso a los ciudadanos es una condición muy desfavorable en la construcción de una cultura urbana y sin duda acelera el advenimiento de una descomposición social en su alrededor.

La sumatoria de los objetos que conforman el mobiliario urbano, junto a las intervenciones artísticas y los follajes de los jardines, debe procurar una escala y una densidad variables que enriquezcan los 
matices de percepción -sin llegar a perder una delicada transparencia- y que garanticen la integración espacial. Esta integración puede brindar un nivel de seguridad apropiado sin anular una intimidad sombría, enriquecida por una variación de proporciones contradictorias.

\section{Bibliografía}

Abalos, Iñaki (2005). Atlas pintoresco. Barcelona: Editorial Gustavo Gili.

Beljon, J. J. (1993). Gramática del arte. Madrid: Celeste Ediciones

Bohigas, Oriol (2004). Contra la incontinencia urbana. Barcelona: Editorial Electa.

Delgado, Manuel. (2005). Revista Mugak \#20: Anonimato y Ciudadanía. San Sebastián: Centro de Estudios y Documentación sobre Inmigración, Racismo y Xenofobia.

Mesa, Felipe. (2006). Copia monográfica Felipe Uribe de Bedout. Bogotá: Panamericana Formas e Impresos S.A.

Careri, Francesco. (2002). Walkscapes, El andar como práctica estética. Barcelona: Editorial Gustavo Gili.

Caveri, Claudio. (2006). Y América, ¿Qué? - Balance entre el ser y el estar como destino del hacer americano y el reflejo en su arquitectura. Buenos Aires: Sintaxis.

Gehl, Jan. (2006). La humanización del espacio público. Barcelona: Editorial Reverte.

Martignoni, Jimena. (2008). Latinscapes, el paisaje como materia prima. Barcelona: Editorial Gustavo Gili.

Mongin, Oliver. (2006). La condición urbana. Buenos Aires: Editorial Paidós

Paris, Omar y Moisset, Inés. (2005). Hipótesis del Paisaje 3-4. Córdoba: I+P Editorial.

Saer, Juan José. (2003). El río sin orillas. Buenos Aires: Seix Barral.

Wilde, Oscar. (2001). Aforismos y paradojas. Bogotá: Villegas Editores.

Yory García, Carlos Mario. (2007). Topofilia o la dimensión poética del habitar (Segunda ed). Bogotá: Editorial Pontificia Universidad Javeriana.

Summary: The modest body skirt is a deeply lyrical action, as well as a writing form in which each passage that is drew up is a story, an intimate history, a calmed weave of memory that turns the actor into author. By this approach, the urban experience like cultural construction is rewritten clearly surpassing, any prediction of behaviour.

Key words: body - emotion - action - furniture - public space - abstraction - city-landscape - climate - rite - event - reaction - urban culture.

Resumo: O modesto contorno do corpo é um ato profundamente lírico, uma forma de escritura em que cada trajeto que traça é um relato, uma história íntima, um tecer sossegado de cor que converte o ator em autor. Deste modo se reescreve a experiência urbana como construção cultural, desde um encofrado predisposto para isso, superando, claro, qualquer predição de comportamento.

Palavras chave: corpo - emoção - ação - mobiliário - espaço público - abstração - cidade-paisagem - clima - rito - acontecimento - evento - reação - cultura urbana.

* Arquitecto urbanista de la Universidad Pontificia Bolivariana (Medellín). Fundador del Estudio Uribe de Bedout arquitectos (1990). Ha sido ganador de varios premios y menciones en las Bienales de Arquitectura de Colombia, Ecuador, 
Brasil e Iberoamericana. Ha participado en calidad de jurado para las bienales nacionales de arquitectura de Puerto Rico y Bolivia; ha sido conferencista invitado en México, El Salvador, Panamá, Venezuela, Argentina y EEUU; profesor titular de la Universidad Pontificia Bolivariana y profesor de su Laboratorio de Estudios Urbanísticos. Desde el 2000 trabaja en importantes proyectos de espacio público de Medellín y como asesor de entidades públicas. 